\title{
Geographic variation in functional and structural traits in ground beetles (the case study of Carabus aeruginosus F.-W., 1822)
}

\author{
Natalya I. Eremeeva ${ }^{1}$, Raisa A. Sukhodolskaya ${ }^{2,}{ }^{*}$, Nadezhda L. Ukhova ${ }^{3}$ and Anatoliy A. Saveliev ${ }^{4}$ \\ ${ }^{1}$ Kemerovo State University Kemerovo, Russian Federation, Russia. \\ ${ }^{2}$ Research Institute for Problems of Ecology and Mineral Wealth Use of Tatarstan Academy of Sciences Kazan, Russian \\ Federation, Russia. \\ ${ }^{3}$ Visimskiy State Reserve Kirovgrad, Russian Federation, Russia. \\ ${ }^{4}$ Kazan (Volga Region) Federal University. Kazan, Russian Federation, Russia.
}

GSC Biological and Pharmaceutical Sciences, 2021, 15(01), 104-111

Publication history: Received on 20 March 2021; revised on 26 April 2021; accepted on 28 April 2021

Article DOI: https://doi.org/10.30574/gscbps.2021.15.1.0110

\begin{abstract}
We sampled beetles by pitfall traps at two sites of its area: Visimskiy Reserve ( $\left(58^{0} \mathrm{~N} 61^{0} \mathrm{E}\right.$, Kirovgrad province, Russia, the western border of area) and Kemerovo city ( $54^{\circ} \mathrm{N} 81^{\circ} \mathrm{E}$, Kemerovo province, Russia, the centre of area). At the first site birch and meadows plots were under study, at the second - meadows and lawns in the residential and industrial zones and the dump in $25 \mathrm{~km}$ from the city. 2109 specimen were measured for six linear traits. Elytra parameters were similar at both regions studied, but another traits (pronotum and head) were significantly larger in the beetles from Reserve. Populations morphometric structure differed significantly at all sites studied. Factors "Province", "Anthropogen", "Biotope" and "Sex" affected beetles body size and structure of its populations. We conclude, that populations at the edge of the area can reproduce and survive successfully due to the mechanism that had been revealed earlier: either body size or the structure of the population change.
\end{abstract}

Keywords: Body size variation; Morphometric structure; Ground beetles; Area theory

\section{Introduction}

Organism body size is a fundamental trait in ecology [1-3]. Body size is correlated with ecological processes across multiple scales, including individual fecundity [4], population biology [5-6], disease transmission [7], food web structuring [8-9] and ecosystem services [10-11]. Understanding variation in body size thus informs both fundamental and applied ecological research.

Based on this assumption, there are numerous studies from multiples disciplines that involve body size as the key aspect of evolutionary adaptation and diversification of organisms [e.g., 12-14]. In this context, variation in body size represents one of the crucial raw materials for evolution to occur.

Body shape morphology is one of primary and utmost simple ways of collecting characteristics of an individual animal and it's applicable for large samples. While complexity of each body part is immense, the utilized methodology in reason of its age prioritized simplicity and robustness. Thus, while certain details might remain unknown, simple metrics should provide insight on most prominent traits.

Conducted research was initially purposed to perceive difference of body shape among sampled Carabids and to reveal influence of environmental factors on studied multitude of metric traits. Each animal was regarded as an object and its

\footnotetext{
* Corresponding author: Sukhodolskaya RA

Research Institute for Problems of Ecology and Mineral Wealth Use of Tatarstan Academy of Sciences Kazan. Russian Federation. 
independent attributes comprised sample specific values of environmental factors' attribute. These values, except for animal specific sex attribute, are shared among the entire sample. Each of metric traits was regarded as a dependent attribute. Values of these are unique for each specimen. Thus, the research was required to demonstrate difference among groups of dependent values, which are selected according to associated independent values.

Presented study is the part of long-termed investigations in ground beetles body size variation. Beginning from 1996 we have been forming the base set in this data, measuring beetles from different part of Russia and abroad [15-16]. Carabids are thought to be the excellent bioindicators, reacting immediately to environments changes [17]. In this case we analyzed body size variation in Siberian species Carabus aeruginosus. Our previous work in this species was conducted with the data set in material sampled in Kemerovo city and its environs. That work had the aim to understand C. aeruginosus body size variation in the gradient of anthropogen impact [18]. In this publication we pursued another goal - to estimate magnitude in C. aeruginosus populations at different parts of its area. Our sampling territories were located thousands of kilometers away - at the west border of area and in the centre. We supposed that: (i) body size in C. aeruginosus would be sex-biased; (ii) factors "Province", "Habitat", "Anthropogen" and their interaction with "Sex" would affect beetles body size; (iii) beetles size in the centre of area would be larger than at the edge.

\section{Material and methods}

\subsection{Study organism}

Carabus (Morphocarabus) aeruginosus was described from "Siberie, Ridders" (present name is Leninogorsk in eastern Kazakhstan), but systematics consider Barnaul environs as a type locality [19]. The wide area of this species is inhabited by many unequally differing populations. Some of the groups of populations, undoubtedly, must be considered as subspecies. At the same time, the majority of populations constitutes a continuous sequence of forms slightly different in size, coloration and proportions, but it is hardly possible to consider these forms as subspecies. A majority of intraspecific names must be treated as synonyms.

C. aeruginosusis is distributed on relatively wide territory - from Ural Mountains till Yakutia and Baikal Lake, and to the North as far as the north-eastern regions of Russia, the Yamal peninsula and the mouth of Yenisei river [20]. Now it is recorded incidentally in the north and at the centre of the eastern part of Russian plane. The species occurs in forests, at the north it can be met in tundra and forest-tundra. Biotopic spectrum is wide-fir-birch and cedar-birch forests, peat-land meadows, woodlands with fern and bootlebrush [20]. The species inhabits urbanized landscapes also, where it is common on the meadows [21]. According to some authors it has been recorded much to the west [22] but present field studies do not confirm this fact.

\subsection{Study sites}

In Kemerovo province $\left(54^{\circ} \mathrm{N} 81^{\circ} \mathrm{E}\right)$ wild specimens of $C$. aeruginosus were sampled in Kemerovo city, its suburbs and in natural habitats outside the city (Table 1).

The habitats studied included forests and meadows as well. The meadows were classified into the forest and true dry ones as well as artificial meadows-lawns. Grass and herb vegetation prevailed at the plots studied. Forest meadows inside the city were the natural territories which had remained in the Rudnichni district pine forest. Additionally we explored carabid population at the dump of solid municipal wastes (Prokopyevsk city in Kemerovo province): on the periphery of the dump (on the slope boards because of continuous movement of garbage in the dump) and in the control (the birch rich-in-herbs forest, close to the dump).

In Kirovograd district (Sverdlovsk province) the beetles were sampled in Visimskiy State Nature Reserve. It is characterized by recovering from several vast wildfires dating 1920, 1998, 2010 in fir dominated areas. Visimskiy reserve is represented by the set of soil zoologic plots (PZP) with each of them corresponding to a different condition of fir forest recovery. Studied species dwells at two plots: PZP 2 and PZP 7. The first while affected only by fire of 2010, exhibits the lowest recovery and assumed as the favorable environment for carabids. PZP7 was affected by fire of 1920 and underwent introduction of significant amount of deciduous species syne, which currently are replaced by fir (Table 1). 
Table 1 Territories where beetles were sampled.

\begin{tabular}{|c|c|c|c|c|}
\hline Province & Locality & Zone & Plot & Sample size \\
\hline \multirow[t]{10}{*}{ Kemerovo } & Kemerovo city & Residential & Filarmonia & 172 \\
\hline & & Residential & Komsomolskiy av. & 398 \\
\hline & & Residential & Khimikov av. & 70 \\
\hline & & Industrial & OAO Azot & 104 \\
\hline & & Industrial & Kemerovo Chemical Enterprise & 433 \\
\hline & & Natural & Sosnoviy Bor & 336 \\
\hline & & Natural & pos. Kedrovskiy & 52 \\
\hline & & Natural & pos. Oktyabrskiy & 35 \\
\hline & Prokopyevsk city & Dump & control & 196 \\
\hline & & Dump & tested & 80 \\
\hline \multirow[t]{2}{*}{ Sverdlovsk } & Visimskiy Reserve & Natural & PZP 2 & 40 \\
\hline & & Natural & PZP 7 & 182 \\
\hline
\end{tabular}

Studied animals were captured using pitfall traps with saline solution. Each sampling site comprised a direct line of traps with over $10 \mathrm{~m}$ distance betwixt each. Sampling trap exposition lasted approximately 5 days length [23]. Subsequently, animals were preserved in $70 \%$ alcohol prior to taxonomic differentiation and were put straightened on cotton paddings thereafter and transferred to the Laboratory of Biomonitoring Research Institute for Problems of Ecology and Mineral Wealth Use of Tatarstan Academy of Sciences for the further analysis. The latter included the following studies:

- Morphometric data was collected from images taken by Nikon D5100 camera with custom opaque light disperser and a box with opaque reflective surface.

- Measurements were made using program, designated specifically for the given method of measurement and utilized distance between manually pointed out elements of photos' arrays as terminal point of measurements and fiducial scale, using the last to bind real scale to array output data.

- Six traits were measured: elytra length and width, pronotum length and width, head length, and the distance between eyes.

In total 2109 specimen were measured. All dimensions (in millimeters) were log10 transformed to ensure normality. Statistical analysis of the morphometric data was performed with R programs [24] (ANOVA) and in Statistica 10 (discriminant analysis). At the first case we estimated the contribution of province, anthropogenic disturbance and type of habitat into the traits variation in C. aeruginosus. At the second we took predictor "locality" (in our case there were Visimskiy Reserve, Kemerovo and Prokopyevsk cities). The box-plots were also constructed in Statistica 10.

\section{Results and discussion}

Elytra lengths were similar in populations from different provinces (Figure 1), but elytra width was larger in beetles from Kemerovo (Figure 2). So, those beetles were slightly stocky. The other traits were significantly smaller in Kemerovo province beetles (Figure 2). 


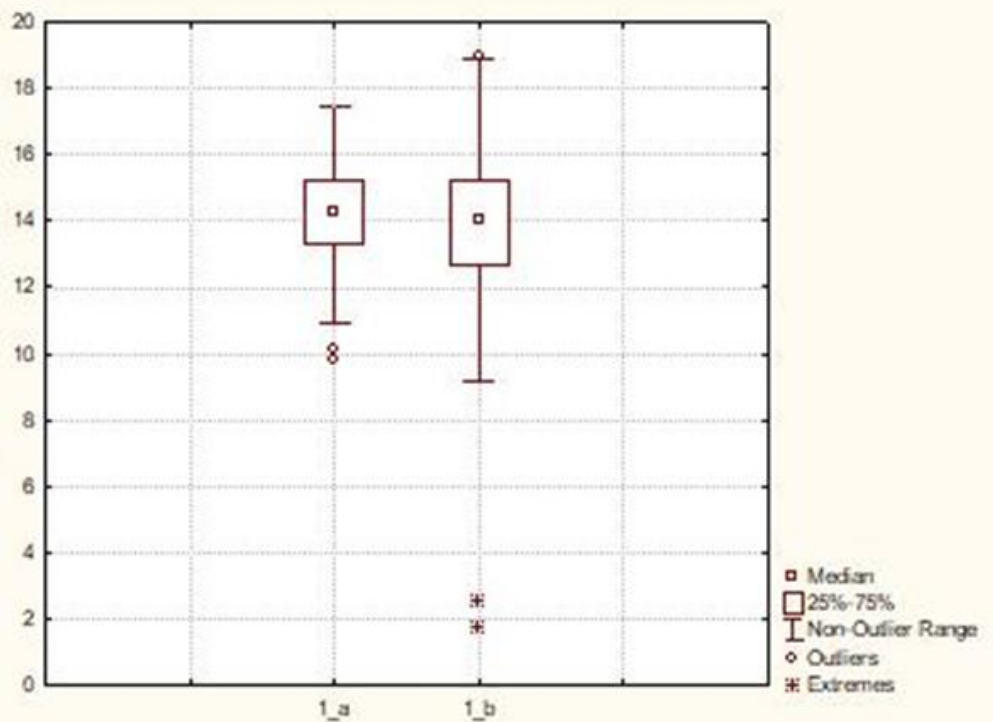

Figure 1 Elytra length in C. aeruginosus from different provinces. a - Kirovograd (Visimskiy Reserve), b - Kemerovo

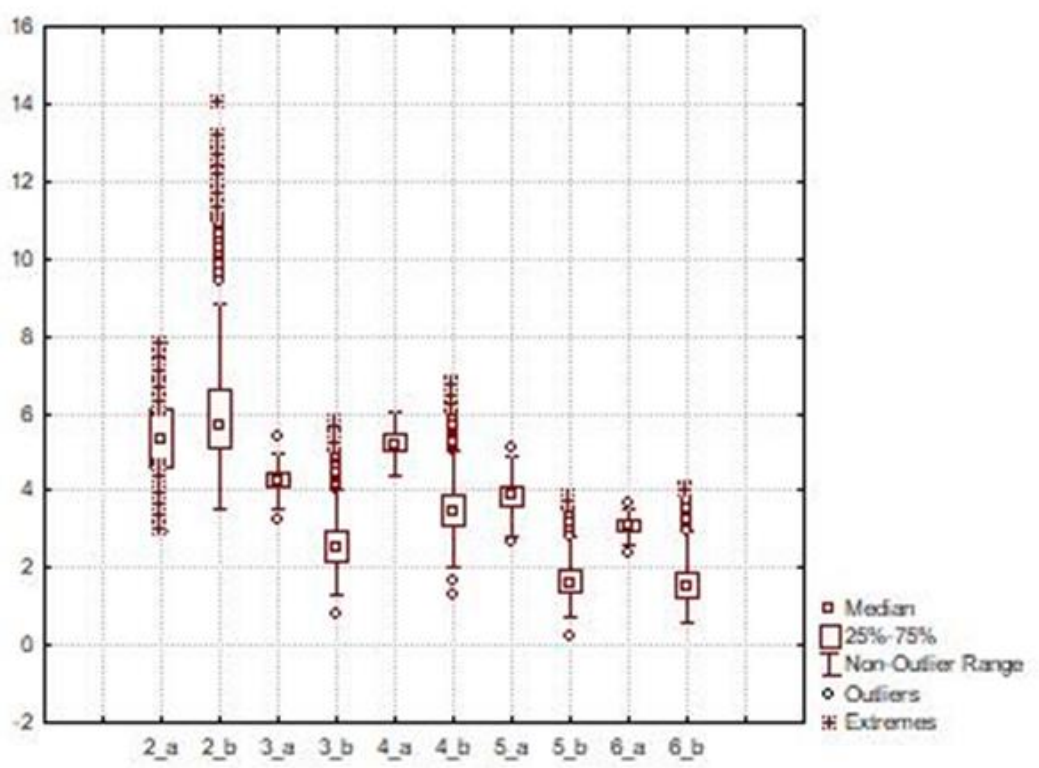

Figure 2 Traits values in C. aeruginosus. 2 - elytra width, 3 - pronotum length, 4 - pronotum width, 5 - head length, 6 - distance between eyes. a - Kirovograd (Visimskiy Reserve), b - Kemerovo

In majority of cases studied all factors affected beetles body size (Table 2): factors "Province", "Biotope" and "Anthropogene" affected all traits in beetles. Besides significant "Biotope*Sex" and "Anthropogene*Sex" interactions were registered. Factor "Sex" affected beetles elytra width, pronotum parameters and distance between eyes, but not elytra length and head length. 
Table 2 MANOVA results in C. aeruginosus body size variation.

\begin{tabular}{|c|c|c|c|c|c|c|c|}
\hline \multicolumn{4}{|l|}{ Elytra length } & \multirow{2}{*}{$\begin{array}{l}\text { Pronotum width } \\
\text { Factor } \\
\end{array}$} & \multirow[b]{2}{*}{ Df } & \multirow[b]{2}{*}{$\mathrm{F}$} & \multirow[b]{2}{*}{ p-value } \\
\hline Factor & Df & $\mathrm{F}$ & $\mathrm{p}$-value & & & & \\
\hline Province & 1 & 21.45 & 0.00 & Province & 1 & 503.87 & 0.00 \\
\hline Biotope & 4 & 98.99 & 0.00 & Biotope & 4 & 1302.39 & 0.00 \\
\hline Anthropogene & 3 & 101.68 & 0.00 & Anthropogene & 3 & 673.42 & 0.00 \\
\hline Sex & 1 & 0.05 & 0.82 & Sex & 1 & 7.08 & 0.01 \\
\hline Province: Sex & 1 & 1.94 & 0.16 & Province: Sex & 1 & 0.54 & 0.46 \\
\hline Biotope: Sex & 4 & 24.86 & 0.00 & Biotope: Sex & 4 & 16.62 & 0.00 \\
\hline Anthropogene: Sex & 3 & 5.57 & 0.00 & Anthropogene: Sex & 3 & 5.51 & 0.00 \\
\hline Elytra width & & & & Head length & & & \\
\hline Factor & Df & $\mathrm{F}$ & p-value & Factor & Df & $\mathrm{F}$ & p-value \\
\hline Province & 1 & 114.82 & 0.00 & Province & 1 & 2244.96 & 0.00 \\
\hline Biotope & 4 & 1165.40 & 0.00 & Biotope & 4 & 1160.23 & 0.00 \\
\hline Anthropogene & 3 & 549.81 & 0.00 & Anthropogene & 3 & 1044.43 & 0.00 \\
\hline Sex & 1 & 6.91 & 0.01 & Sex & 1 & 0.25 & 0.62 \\
\hline Province: Sex & 1 & 0.64 & 0.42 & Province: Sex & 1 & 2.42 & 0.12 \\
\hline Biotope: Sex & 4 & 24.63 & 0.00 & Biotope: Sex & 4 & 4.33 & 0.00 \\
\hline Anthropogene: Sex & 3 & 2.95 & 0.03 & Anthropogene: Sex & 3 & 3.51 & 0.01 \\
\hline Pronotum length & & & & Distance between eyes & & & \\
\hline Factor & Df & $\mathrm{F}$ & $\mathrm{p}$-value & Factor & Df & $\mathrm{F}$ & $\mathrm{p}$-value \\
\hline Province & 1 & 412.88 & 0.00 & Province & 1 & 709.48 & 0.00 \\
\hline Biotope & 4 & 1486.03 & 0.00 & Biotope & 4 & 1650.40 & 0.00 \\
\hline Anthropogene & 3 & 660.48 & 0.00 & Anthropogene & 3 & 825.55 & 0.00 \\
\hline Sex & 1 & 6.22 & 0.01 & Sex & 1 & 12.25 & 0.00 \\
\hline Province: Sex & 1 & 0.10 & 0.75 & Province: Sex & 1 & 0.01 & 0.92 \\
\hline Biotope: Sex & 4 & 13.63 & 0.00 & Biotope: Sex & 4 & 3.86 & 0.00 \\
\hline Anthropogene: Sex & 3 & 1.11 & 0.34 & Anthropogene: Sex & 3 & 1.49 & 0.22 \\
\hline
\end{tabular}

We rearranged date set according to the localities where the beetles were sampled: morphometric structure of those populations differed significantly (Wilks' Lambda: 0457301 approx. F (12.4202) = 1287,304 p <0,0000) (Table 3, Figure 3).

Table 3 Squared Mahalanobis distances in discriminant analysis of $C$. aeruginosus populations ( ${ }^{* * *}$ - p-level<0.000).

\begin{tabular}{|l|l|l|}
\hline & Visimskiy Reserve & Prokopyevk \\
\hline Visimskiy Reserve & 0.00 & \\
\hline Prokopyevk & $60.67^{* * *}$ & $0 ., 00$ \\
\hline Kemerovo & $44.31^{* * *}$ & $23.99^{* * *}$ \\
\hline
\end{tabular}




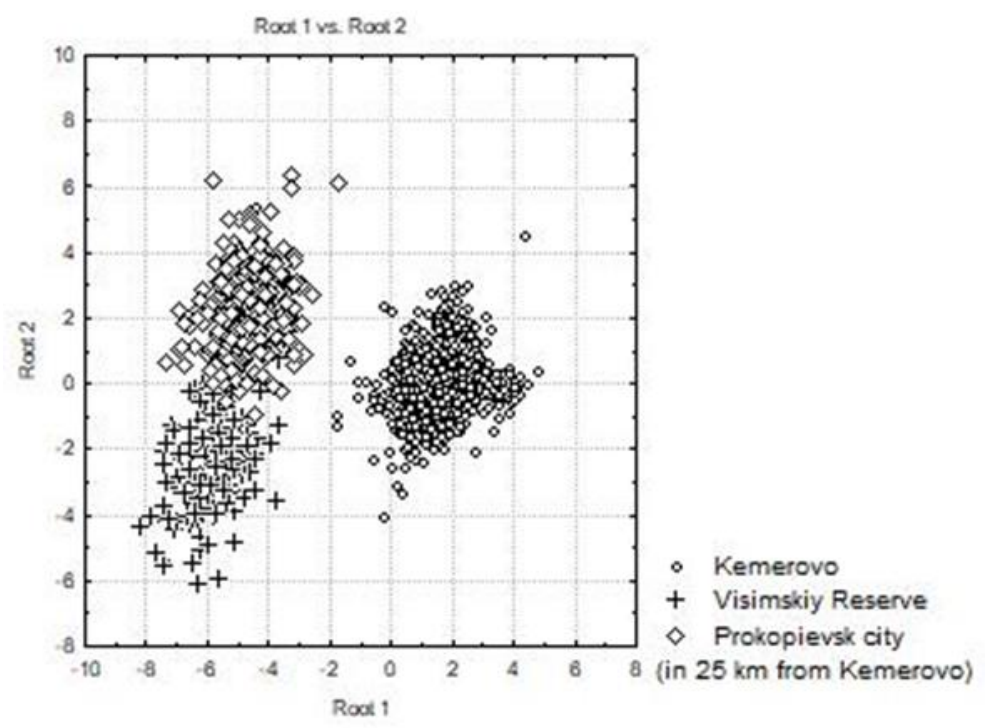

Figure 3 Results of discriminant analysis in populations of C. aeruginosus from different localities

The first publication on $C$. aeruginosus body size variation was carried out in Kemerovo city and its environs: in the gradient of anthropogenic press the smallest beetles habituated residential zone and the largest - natural biotopes [25]. Wherein, morphometric structure in beetle's populations in different zones differed significantly. So, C. aeruginosus is able to adapt to environmental conditions by means of body size variation or the rearrangement in morphometric structure. That thesis was confirmed in our investigation: the size of the beetles was affected by habitation province, anthropogene and biotope. But our results did not confirm our hypothesis: body size in that species was larger at the margin of area. According to classic opinions [26] at the edge of distribution environmental conditions are pessimal for species reproduction and survival. Then, the body size expected to decrease. But another opinion concludes that peripheral populations serve as species ecological and evolutionary reserve and realize tendency to expanse its area and get into a new econiche [27].

Factor "Sex" contributed to traits variation too, but its effect in relation to elytra and head lengths appeared to be insignificant. That fact was inconsistent with another $C$. aeruginosus research, where sexual size dimorphism in that species was strictly female-biased [28]. Separate study on sexual size dimorphism in C. aeruginosus demonstrated that in all samples females were more sensitive to environment than males [29]. The same study revealed that reproduction structure in C. aeruginosus populations at dump in Prokopyevsk changed significantly and it was more similar with the structure of Kemerovo city populations.

\section{Conclusion}

Investigations of animal's traits variation in different parts of area are of great significance. They contribute to the ecogeographical rules interpretation and clarify mechanisms driving evolutionary process. In relation to climate change different efforts need in study of body size and morphometric structure variation as the phases of ground beetles adaptation to the heterogeneous environment. Our results showed that beetles adaptation can be expressed in both body size and population morphometric structure variation.

\section{Compliance with ethical standards}

\section{Acknowledgments}

The authors thank the staffs of Visimckiy Reserve, Department of Ecology and Nature Management of Kemerovo State University for beetles sampling and Junior Researchers of Laboratory of Biomonitoring IPEN AN RT Dmitriy Vavilov and Anton Sobolev for data processing. 


\section{Disclosure of conflict of interest}

The authors report no conflicts of interest. The authors alone are responsible for the content and writing of this article.

\section{References}

[1] Calder WAI. Size, function and life history. Mineola, NY: Dover Publications, USA. 1996.

[2] Kingsolver JG, Huey RB. Size, temperature, and fitness: Three rules. Evolutionary Ecology Research. 2008; 10: 251-68.

[3] Peters RH. The ecological implications of body size. Cambridge: Cambridge University Press, UK. 1983.

[4] Honĕk A. Intraspecific variation in body size and fecundity in insects: A general relationship. Oikos. 1993; 66: 483-92.

[5] Siemann E, Tilman D, Haarstad J. Insect species diversity, abundance and body size relationships. Nature. 1996; 380: 704-06.

[6] White EP, Ernest SKM, Kerkhoff AJ, Enquist BJ. Relationships between body size and abundance in ecology. Trends in Ecology \& Evolution. 2007; 22: 323-30.

[7] Russell TL, Lwetoijera DW, Knols BGJ, Takken W, Killeen GF, Ferguson HM. Linking individual phenotype to density-dependent population rowth: The influence of body size on the population dynamics of malaria vectors. Proceedings of the Royal Society B: Biological Sciences. 2011; 278: 3142-51.

[8] DeLong JP, Gilbert B, Shurin JB, Savage VM, Barton BT, Clements CF, O'Connor MI. The body size dependence of trophic cascades. The American Naturalist. 2015; 185: 354-66.

[9] Griffiths D. Size-abundance relations in communities. The American Naturalist. 1986; 127: 140-66.

[10] Baudron AR, Needle CL, Rijnsdorp AD, Tara Marshall C. Warming temperatures and smaller body sizes: Synchronous changes in growth of North Sea fishes. Global Change Biology. 2014; 20: 1023-31.

[11] Sheridan JA, Bickford D. Shrinking body size as an ecological response to climate change. Nature Climate Change. 2011; 1: 401-06.

[12] Blanckenhorn WU. The evolution of body size: what keeps organisms small? The Quarterly Review of Biology. 2000; 75: 385-407.

[13] Huang S, Eronen JT, Janis CM et al. Mammal body size evolution in North America and Europe over 20 Myr: similar trends generated by different processes. Proceedings of the Royal Society B: Biological Sciences. 2017; 284: 20162361.

[14] Kruuk LEB. A new explanation for unexpected evolution in body size. PLoS Biology. 2017; 15: e2001832.

[15] Sukhodolskaya RA. Intraspecific body size variation in Ground Beetles (Coleoptera, Carabidae) in urbansuburban-rural-natural gradient. Acta Biologica Universitatis Daugavpiliensis. 2013; 13(1): 121-28.

[16] Sukhodolskaya RA, Ananina TL. Altitudinal variation in population density, body size and morphometric structure in Carabus odoratusShil, 1996 (Coleoptera: Carabidae). Biologica Universitatis Daugavpiliensis. 2015; 15 (1): 179-90.

[17] Koivula MJ. Useful model organisms, indicators, or both? Ground beetles (Coleoptera, Carabidae) reflecting environmental conditions. ZooKeys. 2011; 100: 287-17.

[18] Sukhodolskaya RA, Eremeeva NI. Body size and shape variation in Ground Beetle Carabus aeruginosus F.-W., 1822 (Coleoptera, Carabidae). Contemporary Problems of Ecology. 2013; 6(6): 609-15.

[19] Obydov D. A revision of "Carabus aeruginosus" species group (Coleopera, Carabidae). Coléptéres. 1999; 5(9): 14974.

[20] Obydov D. A new subspecies of Carabus (Morphocarabus) aeruginosus Fischer Von Wildheim, 1822 (Coleoptera, Carabidae) from East Sayan Mountains (East Siberia). Munis Entomology \& Zoology. 2011; 1: 146-49.

[21] Savosin, NI. Dominant species of ground beetles (Coleoptera, Carabidae) in herpetobiontic communities in Kemerovo city. Tr. Kemer. Otd. Russ. Entomol. Ob-va. 2008; 6: 105-09. 
[22] Kryžanovskij OL. A checklist of the ground-beetles of Russia and adjacent lands (Insecta, Coleoptera, Carabidae). No. 3. Pensoft publishers. 1995.

[23] Barber HS. Traps for cave-inhabiting insects. Journal of the Elisha Mitchel Scientific Society. 1931; 46(2): $259-66$.

[24] R Development Core Team. R: A Language and Environment for Statistical Computing. R Foundation for Statistical Computing, Vienna, Austria. 2018.

[25] Timofeeva GA. Morphometric structure of carabids (Coleoptera, Carabidae) at the territories with different anthropogenic effect. PhD Thesis. Kazan, Russia. 2009.

[26] Solbrig OT, Solbrig DJ. Introduction to Population Biology and Evolution. Addison-Wesley Publishing Company Reading, Massachusetts. Menlo Park, California, USA. 1982.

[27] Ivanter EV. The development of the concept of polytypical species peripheral populations. Populyatcionnaya ecologia zshivotnikh. Proceedings of the International conference. Tomsk, Russia. 2006; 32-34.

[28] Sukhodolskaya RA, Saveliev AA, Muhammetnabiev TR. Sexual Dimorphism of Insects and Conditions of Its Manifestation. Research Journal of Pharmaceutical, Biological and Chemical Sciences. 2016; 7(2): $1992-2001$.

[29] Sukhodolskaya RA, Eremeeva NI, Saveliev AA. Urbanization effect on sexual size dimorphism in ground beetle Carabus aeruginosusF. - W. Bioraznoobrazie i antropogennaya transformatcia prirodnikh ecosystem. Proceedings of VIII All-Russia conference. Saratov, Russia. 2020; 66-69. 